\title{
La novela ecuatoriana en el siglo xx, según Alicia Ortega Caicedo
}

\author{
Raúl Vallejo \\ Universidad de las Artes, Guayaquil, Ecuador \\ banano@uasb.edu.ec
}

Recibido: 11 - noviembre-2018 / Aceptado: 21 -diciembre-2018

\section{Resumen}

Desde que Ángel Felicísimo Rojas escribió La novela ecuatoriana (1948), no se había escrito una obra monumental como esta. Fuga hacia adentro. La novela ecuatoriana en el siglo XX, de Alicia Ortega, es un trabajo que por su envergadura y profundidad está llamado a ser parte indispensable de la tradición crítica del Ecuador. En este artículo, su autor expone, de manera descriptiva, las principales tesis desarrolladas por Ortega en su libro y comenta, cuando es del caso, la ubicación que estos nuevos planteamientos tienen en la tradición crítica ecuatoriana. Este artículo consigue una apretada síntesis de los principales postulados que se encuentran en el ensayo de Ortega.

Palabras clave: crítica ecuatoriana, novela ecuatoriana del siglo XX, Ángel Felicísimo Rojas, memoria y literatura, tradición y modernidad.

\section{Abstract}

Since Angel Felicísimo Rojas wrote La novela ecuatoriana (1948), there has been no other work as monumental as this. Alicia Ortega's Fuga hacia adentro. La novela ecuatoriana en el siglo $X X$, is a book that, because of its magnitude and depth, is destined to be an essential part of the critique tradition in Ecuador. In this article, the author explains, in a descriptive manner, the main theses developed by Ortega in her book and comments, 
when necessary, the place this new statements have in the critique tradition in Ecuador. This article achieves a tight synthesis of the principal propositions that can be found in Ortega's essay.

Keywords: ecuadorian critique, ecuadorian novel of the XX century, Angel Felicísimo Rojas, memory and literature, tradition and modernity. 
$\mathrm{E}$ n 1948, apareció La novela ecuatoriana, de Ángel Felicísimo Rojas, un texto que habría de marcar no solo la visión de la literatura producida hasta entonces, sino también el camino que seguiría la crítica sociológica en nuestro país. Con el paso del tiempo, que todo lo decanta, aquel libro se convirtió en un paradigma de la crítica literaria. Sus juicios, inscritos en la disputa entre una visión liberal y otra conservadora, atravesados por la militancia socialista del propio Rojas, quedaron como referentes para continuar el estudio de nuestra novelística. Para él, política y literatura son esferas inseparables del hacer intelectual, y así lo señala en el párrafo de apertura de su texto:

Los escritores de esta parte de América, como de ninguna otra quizá, rara vez han escatimado la intervención activa en la política nacional y, por lo mismo, las obras de ficción del Ecuador son una forma de esa actitud. El conocido apotegma de que la literatura es la traducción de un estado político y social, sentido por ellos más que deliberado, está presente en lo más representativo de sus producciones novelescas. ${ }^{1}$

De ahí que el método de exposición de Rojas comienza con una visión histórica correspondiente a la época analizada, continúa con el comentario de las obras significativas del período en cuestión y termina con una serie de conclusiones y confirmaciones que, en definitiva, son las tesis desarrolladas.

En 2018, Alicia Ortega Caicedo publica Fuga hacia dentro. La novela ecuatoriana en el siglo XX. Así como Rojas partió de la aceptación de que los escritores eran también sujetos políticos, Ortega se interesa por esa compleja relación entre literatura y crítica por cuanto en ella están en juego mucho más que meros planteamientos estéticos:

Lo que está en juego es una forma de comprender la construcción del sujeto en el lenguaje: el sujeto que lo enuncia y el sujeto referido en él. Lo que está en juego es el lugar del sujeto en el mundo que ese lenguaje construye en el relato, así como el lugar del sujeto en el mundo que hace posible ese lenguaje. ${ }^{2}$

Ortega evita el tipo de visión panorámica de tantos manuales que, por intentar abarcarlo todo, carecen de profundidad al momento de comentar los textos, darles su lugar en la historia literaria, y termina por ser un catálogo de publicación. Ortega lo hace desde una posición arriesgada pero necesaria que selecciona textos que, a su criterio, marcaron hitos en el devenir de la novela ecuatoriana. La selección de los textos es, en sí misma, una decisión crítica que, sin proponérselo construye un canon que posibilita nuevas lecturas de la historiografía novelística. $\mathrm{O}$, como ella mismo señala: «La apuesta crítica por una tradición es, necesariamente, una tarea

1 Ángel Felicísimo Rojas, La novela ecuatoriana, en Obras completas. Ensayo, Tomo III (Loja: Universidad Técnica Particular de Loja, 2004), 57.

2 Alicia Ortega Caicedo, Fuga hacia dentro. La novela ecuatoriana en el siglo XX (Buenos Aires: Corregidor / Universidad Andina Simón Bolívar, Sede Ecuador), 26. 
de selección que visibiliza unos textos y descuida otros. Los títulos y autores que destaco devienen hilos de una tradición literaria, que me han ayudado a marcar los cortes y las pausas de este trayecto». ${ }^{3}$

Al mismo tiempo, Ortega desarrolla una estrategia de lectura de los avatares de la crítica, respecto de aquellas novelas, introduciéndose así en una tradición enriquecida por las diferentes lecturas de quienes trabajaron la novelística del siglo pasado, y contribuye también a problematizar la posición del escritor en tanto intelectual en el ámbito político y cultural del país. Al parecer, el siglo veinte, pero, más que todo, su segunda mitad, está atravesado por el hecho de que «la representación del intelectual es eje articulador de la ensayística, así como motivo central en un significativo corpus novelístico». ${ }^{4}$ Para la primera mitad, Ortega señala lo que será la preocupación política de la llamada Generación del 30:

En esta perspectiva, el intelectual de nuevo cuńo legitima la autoridad de su proyecto literario en su doble rol de escritor y ensayista, puesto que el cometido fundamental es la producción de una literatura, y de una crítica literaria, de carácter nacional, en la perspectiva de consolidar una conciencia nacional. ${ }^{5}$

Tanto Ortega como Rojas señalan esta presencia de lo político en la vida de los escritores devenidos en intelectuales que no solo se han preguntado por lo nacional sino que trabajaron, de manera militante, en la construcción de esa nación, desde variados proyectos literarios. Ortega, que pone al día los planteamientos de Rojas para principios del siglo pasado, señala que los escritores lo hicieron, en la primera mitad, anclados en la voluntad de realismo; en la segunda, después de la Revolución Cubana, bajo las consignas de Gramsci y Sartre sobre la función y el compromiso de los intelectuales, con el anhelo de "desprovincializar" la literatura. Particularmente, en los ochenta, Ortega se pregunta sobre la incidencia en la literatura que tuvo el llamado desencanto de la posmodernidad; y en los noventa, la aparición de nuevas subjetividades. En una reseña reciente, Michael Handelsman, señala sobre estos asuntos tratados en el libro de Ortega:

[...] Fuga hacia dentro nos convoca a todos a pensar decolonialmente para así romper con rancias tradiciones dualistas como civilización y barbarie, realismo y vanguardia, tradición y modernidad, localismo y cosmopolitismo. En el fondo, las disquisiciones críticas de Ortega ponen en debate el sentido mismo del intelectual frente a la representación como apuesta estética y ética, pero ahora entendida complementariamente. ${ }^{6}$

3 A. Ortega Caicedo, Fuga hacia dentro, 433.

4 Ibíd., 9.

5 Ibíd., 13.

6 Michael Handelsman, "Alicia Ortega Caicedo. Fuga hacia adentro. La novela ecuatoriana en el siglo XX”, en Pie de página, \# 1 (Guayaquil), octubre 2018, pp. 138-139. 
Ortega plantea que, en la primera mitad del siglo veinte, los novelistas hacían una literatura pensada en la exploración de los elementos constitutivos de lo nacional, no desde el folclore sino desde el estudio de campo de la realidad que transformaban en literatura. Ortega plantea que $A$ la costa, de Luis A. Martínez, es una novela precursora de la narrativa del 30. En esto coincide con Rojas, quien señala que «la crítica contemporánea viene considerándola, a la par que como un documento realista de valor inestimable, como un creación artística en extremo afortunada». ${ }^{7}$ Pero Ortega, al analizar el período va más allá de las reflexiones de Rojas y, por ejemplo, nos descubre la manera como los escritores de entonces tenían conciencia plena de la estética que estaban desarrollando ya que aportaban desde sus ensayos a la caracterización de su propia literatura:

Es posible establecer un sinnúmero de paralelos entre El montuvio ecuatoriano y Los Sangurimas: la concepción de los personajes, sus relaciones afectivas, la configuración de la familia Sangurima como entidad casi aislada y organizada alrededor de su progenitor masculino más viejo, la representación de la sexualidad y la ausencia del tabú del incesto; la determinación geográfica. El montuvio ecuatoriano participa del propósito conjunto de una generación al proveer elementos que nutren y configuran los nuevos imaginarios de la nación y de la literatura por venir. ${ }^{8}$

Este señalamiento es necesario de ser resaltado porque, muchas veces, ciertos escritores adánicos de hoy -desinformados, prejuiciados y arrogantes- creen que la literatura del 30 respondió únicamente al espíritu folclórico y a la militancia política, cuando, desde la perspectiva actual, puede verse como otra forma de manifestación de la vanguardia, según los postulados de Mariátegui, que aclara bastante bien la cuestión en contrapunto con Huidobro, al señalar el camino político seguido por Louis Aragón y André Bretón hacia el comunismo e, incluso, el de Drieu La Rochelle hacia el fascismo:

Vicente Huidobro pretende que el arte es independiente de la política. Esta aserción es tan antigua y caduca en sus razones y motivos que yo no la concebiría en un poeta ultraísta, si creyese a los poetas ultraístas en grado de discurrir sobre política, economía y religión. Si política es para Huidobro, exclusivamente, la del Palais Bourbon, claro está que podemos reconocerle a su arte toda la autonomía que quiera. Pero el caso es que la política, para los que la sentimos elevada a la categoría de una religión, como dice Unamuno, es la trama misma de la Historia. En las épocas clásicas, o de plenitud de un orden, la política puede ser sólo administración y parlamento; en las épocas románticas o de crisis de un orden, la política ocupa el primer plano de la vida. ${ }^{9}$

7 A. F. Rojas, La novela ecuatoriana, 166.

8 A. Ortega Caicedo, Fuga hacia dentro, 52.

9 En "Arte, revolución y decadencia”, inicialmente publicado en la revista Amauta, \# 3 (Lima, noviembre 1926) No 3 , 3-4. Tomado del sitio web donde están subidas las obras completas de José Carlos Mariátegui: https://www.marxists.org/ espanol/mariateg/oc/el_artista_y_la_epoca/paginas/arte\%20revolucion\%20y\%20decadencia.htm 
Un capítulo notable del ensayo de Ortega es aquel en donde describe y analiza las disputas y encuentros del realismo con la vanguardia. Ella realiza afirmaciones fuertes, a contracorriente pero mejor informadas, como la de indicar que «Icaza y Palacio son dos escritores que guardan más puntos de contacto que los que la crítica tradicionalmente ha querido ver». ${ }^{10}$ La reflexión de Ortega engloba el contexto de la producción de las obras y en donde toman lugar las controversias, lo que le permite una visión clarificadora sobre estas últimas. Así, dentro de la tarea de construir una tradición literaria que nos permita entender que la novelística del Ecuador de hoy no emerge de la nada, Ortega puntualiza frente a la polémica del realismo con la vanguardia:

Se trata de una disputa, la de Gallegos Lara y Palacio, que, aunque en principio fue leída y comprendida como el enfrentamiento de dos modos de entender la literatura, desde la perspectiva del siglo conviene insistir en que lo que está en discusión es el sentido y la función de la literatura en la sociedad, así como la relación entre la vanguardia artística y la vanguardia política. ${ }^{11}$

Ortega, que además de ser una académica que investiga, es una intelectual que expone sus ideas con mucho vuelo creativo, habla de la fuga hacia adentro en la novelística ecuatoriana del siglo veinte. Al analizar los textos de la primera mitad del siglo pasado, establece el sentido de aquella fuga, no desde la especulación burocrática sino desde la lectura de los textos y de lo que de ellos se desprende. Transcribo in extenso una reflexión que incluye un ejemplo literario para exponer de mejor manera esta característica del ensayo de Ortega:

En las novelas es posible reconocer un relato de fundación y origen, así como el impulso de la fuga y el desplazamiento. Sin embargo, tal motivo, el de la fuga, no responde a ningún impulso de vida errante ni "sed de infinito", o deseo de aventura (elementos que suelen señalarse como característicos de la vida contemporánea). Los personajes en fuga -porque huyen de la policía rural, de quienes representan al gobierno, del enganchador, del patrón, de la pobreza- responden a una lógica de violencia y a una necesidad de vida en clave de supervivencia: "¿Has visto la basurada del río? Mala comparación, pero así somos. De un lado a otro. Con la creciente subimos, con la vaciante bajamos. Y en veces las revesas...", comenta un personaje de Nuestro pan. Si el relato de fundación apunta a dotar de elementos simbólicos a un imaginario plural de nación, el tema de la fuga revela las fisuras y las grietas de ese mismo proyecto. ${ }^{12}$

Un capítulo excepcional es el dedicado a la novelística de Jorge Icaza, cuya obra "puede ser leída como una peregrinación narrativa que indaga en torno a la identidad de un complejo y heterogéneo mundo mestizo; un mundo marcado por desencuentros exclusiones, violencias y rivalidades». ${ }^{13}$ Además de recorrer y confrontar,

\footnotetext{
10 A. Ortega Caicedo, Fuga hacia dentro, 65.

11 Ibíd., 65.

12 Ibíd., 145.

13 Ibíd., 151.
} 
con agudos contrapuntos, las controversias que ha desatado la obra de Icaza, Ortega reafirma -más allá de los aspectos sociológicos que subyacen en estas y que también son estudiados- la valoración de las novelas de Icaza desde su aporte al lenguaje literario y desde la estructura implementada por Icaza en su narrativa. Ortega seńala que la vigencia de Huasipungo no es consecuencia únicamente de su valor documental sino también de la estrategia literaria que desarrolla:

\begin{abstract}
Diálogos, imágenes, situaciones, personajes, son construidos en el tramado de un lenguaje potente, que rompe con toda mesura gramatical en un permanente ejercicio de torsión y quiebre del código realista. [...] En el caso de Icaza se trata de una lengua literaria que recrea el lenguaje popular de la Sierra ecuatoriana, claramente influida por el quichua en la percepción y formalización del oído mestizo (el del autor). Icaza no teme quebrar el pacto ficcional, para crear en el lector la "ilusión" de asistir a una puesta en escena de hiperbólica verdad y valor documental. En función de ello, la voz autoral reproduce el acto subjetivo de la percepción: repite, enumera, hiperboliza, en el transcurso de una narración que se violenta a sí misma en el acto mismo de narrar la violencia. ${ }^{14}$
\end{abstract}

Ortega considera a la narrativa de Icaza, en su conjunto, como hito fundamental para problematizar la noción de mestizaje; por eso, analiza también Huairapamushcas, Mama Pacha, y El chulla Romero y Flores, con todas las contradicciones inherentes que el mestizaje propone, en tanto proyecto de una nación que, en su estructura, es plural y diversa. Hoy día, con la emergencia de los pueblos originarios, la nación ha superado el entendimiento de sí misma como una sociedad exclusivamente mestiza para dar paso a la noción del Estado plurinacional, y Ortega no deja de señalar esta situación en su análisis.

La segunda parte del libro de Ortega reflexiona sobre la novelística de la segunda mitad del siglo veinte. Sus preocupaciones iniciales se asientan en las representaciones del sujeto intelectual a partir de tres novelas de los cuarenta: Hombres sin tiempo, de Alfredo Pareja Diezcanseco; Las cruces sobre el agua, de Joaquín Gallegos Lara; y Los animales puros, de Pedro Jorge Vera. Esa representación literaria está planteada en todas sus contradicciones, lo que implica el desgarramiento interior, la imposibilidad de realización de la utopía revolucionaria, y las limitaciones que el origen de clase impone a esos intelectuales al momento de querer ser parte del movimiento popular. Ortega hará el seguimiento del intelectual a lo largo del siglo:

Sin duda, la figura del intelectual ha ocupado un lugar central en la producción literaria: por un lado, en tanto motivo de ficcionalización (el intelectual como personaje y protagonista de una narración) y, por otro, cada nueva generación de escritores y críticos ha construido una nueva narrativa de autopercepción como estrategia de afirmación y prestigio en el campo cultural del presente. ${ }^{15}$ 
Luego vendrá el tiempo del parricidio y la crítica a la ciudad letrada. En este capítulo, Ortega pasa revista por la ruptura con la estética de la generación del 30 a través de la actitud parricida, la ruptura con la mediación estatal del hacer cultural y la irrupción estética más performática que textual de los Tzántzicos. Aunque parecería que sus actitud política fue fundacional, en realidad, fue continuidad de una larga tradición de escritores que asumieron sus tareas de intelectuales, tradición que se remonta a los escritores románticos del siglo diecinueve y que, en el siglo veinte tiene militantes liberales, socialistas y comunistas. Su actitud iconoclasta los llevó a cuestionar el concepto de mestizaje y, al mismo tiempo, plantearse como objetivo la construcción de una "auténtica cultura nacional y popular", inspirados en el triunfo de la Revolución Cubana y buscando su legitimación, nuevamente, en la militancia política. Ortega señala, sobre la actitud cultural de los tzántzicos:

Los recitales tzántzicos -en su afán provocativo y desacralizador, su nivel sorpresivo, la búsqueda de impacto social y el empeño por apelar a la sensibilidad, la politización del arte y el compromiso con la escena contemporánea- guardan cierta sintonía con la performance y el happening (inevitable no pensar la primera intervención del grupo, "Cuatro gritos", en diálogo con "Aullido" de Allen Ginsberg). ${ }^{16}$

En ese contexto, Ortega lleva adelante un inteligente contrapunto con Agustín Cueva y su crítica cultural y literaria, a partir de Entre la ira y la esperanza y, más adelante, la polémica desatada por el mismo Cueva frente a la literatura de Icaza y Palacio, punto sobre el que volveré más adelante. En este punto, Ortega seńala la transición de los tzántzicos hacia lo que fue la experiencia del Frente Cultural y la revista La bufanda del sol, a fines de los 60 y comienzos de los 70, que aglutinó a los representantes de la entonces "nueva narrativa ecuatoriana".

Ortega señala que esta generación «se caracteriza por una consciente voluntad de romper con los parámetros del realismo» y, por ello se caracteriza por las siguientes preocupaciones, que señalo textualmente, según lo descrito más extensamente por ella: a) predilección por escenarios urbanos; b) tendencia a la interiorización y al ahondamiento en la subjetividad de los personajes; c) presencia sobresaliente de personajes desarraigados; d) preocupación constante por el lenguaje; e) los escritores buscan, en la línea de Palacio, descreditar la realidad. En síntesis:

Se persigue develar las contradicciones y prejuicios de una sociedad conservadora y represiva que aún lleva el peso de la Colonia. De allí que el tema de la familia y las relaciones de pareja ocupen un lugar privilegiado. El mundo de la cotidianidad se impone y la narrativa se abre hacia nuevos ámbitos temáticos: la infancia, la vida de barrio, las cofradías, la sexualidad. ${ }^{17}$

16 Ibíd., 251.

17 Ibíd., 269. 
Las reflexiones siguientes sobre Entre Marx y una mujer desnuda, de Jorge Enrique Adoum, y Polvo y ceniza, de Eliécer Cárdenas, trabajan sobre la conciencia del intelectual y el fracaso del pacto heroico entre el poeta y el bandido. Ortega analiza con agudeza los niveles narrativos de Entre Marx..., y la presencia permanente del conflicto del intelectual, así como la hiperconsciencia del acto narrativo y la argumentación metaliteraria sobre el acto de escritura. Esta novela de Adoum es un hito fundamental de la narrativa del último cuarto de siglo, no solo por la solvencia de su escritura, la coherencia interna de su composición, y la radical experimentación de su lenguaje y estructura, sino porque en ella, su autor aborda una gama de temáticas que van desde la reflexión sobre la tarea de los intelectuales y las opciones de estética literaria; pasa por los diversos estadios de la experiencia amorosa, y, además, engloba una visión autocrítica del país y su gente, en medio de las contradicciones de su devenir histórico. Adoum convoca a la figura de Gallegos Lara, y el debate sobre la militancia y la literatura gana espesor en esta novela, según lo señala Ortega:

Gallegos Lara deviene símbolo como figura intelectual en la medida en que, a pesar de sus limitaciones físicas, fue quien más se aproximó a la idea de un "intelectual orgánico"; una figura que, en el marco de su biografía y de la historia nacional, asume una cierta estatura heroica. Es un personaje indispensable, continúa el "autor problemático", en un libro que habla sobre el fracaso de una generación - "mutilada", por carecer de "hombres de acción"; que replica el viejo tópico de la disputa entre las armas y las letras-, de un partido, de un país, "como república" y de la literatura "como arma y como literatura": "Me es indispensable ese personaje de tragedia griega que consiguió en medio del trópico lo insólito: ser héroe cada día en una sociedad que no tiene nada de heroico" [citando un texto de la novela] ${ }^{18}$

El tratamiento novelesco que Adoum le da a la problemática del escritor, sus niveles de consciencia, y la disyuntiva que enfrenta entre la vivencia plena del amor, la realización espiritual que implica la literatura y los avatares y sacrificios que son inherentes a la militancia política, están planteados de tal manera que hacen de Entre Marx..., una novela de un vitalismo excepcional por cuanto aborda la complejidad de la existencia desde sus múltiples aristas. Continuando con la idea del intelectual y su relación con el pueblo, Ortega observa que en Polvo y ceniza, esa relación del poeta y el bandido es clave para entender la compleja participación del intelectual en la política:

Un episodio clave de la novela es el encuentro entre Naún Briones y Víctor Pardo, el joven poeta y bachiller. Se trata del encuentro conflictivo entre dos conciencias; entre dos patrones culturales radicalmente distintos: el de la originalidad, propio de quien "estudia en los libros siempre abiertos de la vida”, y el de la escritura. Más aún, lo que está en disputa es el debate sobre el rol de la literatura, y del escritor, en la sociedad; caro tema a los intelectuales y escritores de la década del setenta. ${ }^{19}$

18 Ibíd., 293.

19 Ibíd., 296. 
Ese encuentro y lo que se deriva de él, al parecer, está destinado al fracaso, pues «ambos se estrellan contra la soledad y la muerte». ${ }^{20}$ Ortega analiza el sentido trágico de dicho fracaso, tanto en Entre Marx... como en Polvo y ceniza y concluye que la imposibilidad de la revolución, objetivo del proyecto intelectual de quienes estuvieron animados por la esperanza de justicia social y soberanía que generó la Revolución Cubana, demuestra el fracaso de la alianza entre el intelectual y el hombre del pueblo. De ahí que las últimas décadas se caracterizarán por el desencanto, como actitud espiritual frente al mundo.

Ortega pasa revista a los debates que, en las dos últimas décadas del siglo veinte, se desarrollan sobre la modernidad, el desencanto y las nuevas sensibilidades literarias. Estos debates estuvieron protagonizaos por Agustín Cueva, Fernando Tinajero, Miguel Donoso Pareja, Jorge Enrique Adoum, María Augusta Vintimilla, Alejandro Moreano, Diego Araujo, y otros. Ortega logra armar el diálogo de esos años frente al tema del realismo, el llamado "realismo abierto" y la increíble continuidad de la polémica entre Gallegos Lara y Pablo Palacio, que revela no solo la permanencia de la preocupación sobre la relación del intelectual y el tiempo político que le toca, sino también la incapacidad para reconocer, desde nuevas y atentas lecturas, todo lo que se ha producido en nuestra tradición literaria.

Bastaría con señalar que el mito que ha hecho de Palacio un escritor "marginal" y "no reconocido" por la crítica se cae a pedazos si se investiga un poco. Desde un comienzo, para mencionar solo unos pocos ejemplos, su literatura fue señalada en toda su valía por la crítica. Lo hizo Benjamín Carrión en Mapa de América (1930), en un artículo que propuso las tesis básicas con las que Palacio ha sido leído y analizado hasta hoy; Ángel F. Rojas le dedica un par de elogiosas páginas en La novela ecuatoriana (1948); la Casa de la Cultura Ecuatoriana, bajo la presidencia de Jaime Chaves Granja, publicó sus Obras completas en 1964; y los escritores de la revista La bufanda del sol lo reivindicaron como propio en 1974, tanto a él como, en otro número de la revista, a José De la Cuadra. ${ }^{21}$

Ortega analiza, sobre todo, la polémica entre Agustín Cueva, a partir de su artículo "Collage tardío en torno de l'affaire Palacio» (1991), y Miguel Donoso, quien coordinó en 1987 un volumen de estudios de corte académico dedicados a la obra de Palacio y publicado por Casa de las Américas en su serie "Valoración Múltiple". Esa polémica giraba respecto a la obra de Gallegos Lara, Icaza y Palacio, el tema del realismo y el anti-realismo, y el lugar que cada uno ocupa en la tradición de la literatura ecuatoriana. Ortega señala, con mesura, lo que, finalmente, ha desarrollado con inteligencia en la escritura de su libro:

20 Ibíd., 269, 297.

21 Un amplio análisis de la obra de Palacio puede consultarse en Pablo Palacio, Un hombre muerto a puntapiés y otros textos (Caracas: Biblioteca Ayacucho, \# 231, 2005); cuya compilación, prólogo, cronología y bibliografía estuvieron a mi cargo. 
Más allá de los múltiples desencuentros y mutuas aclaraciones entre Cueva y Donoso, menciono el debate, pues generó una interesante y rica reflexión en torno al realismo. Más importante aún, la disputa en torno al realismo, así como la pregunta por el impacto y trascendencia de la obra de Icaza y Palacio, posibilitó que toda una generación de críticos y escritores definiera su lugar de enunciación así como la construcción de sus filiaciones y horizontes de escritura. ${ }^{22}$

Ortega trabaja con las novelas Ciudad de invierno y Sueño de lobos, de Abdón Ubidia, Nunca más el mar, de Miguel Donoso Pareja, El rincón de los justos, de Jorge Velasco Mackenzie, y La cofradía del mullo del vestido de la Virgen Pipona, de Alicia Yánez Cossío. A través de ellas, va recorriendo la emergencia del espíritu de una nueva época, esa que advino en el país luego del boom petrolero y que transformó de muchas formas los afectos, las subjetividades y los modos sociales de entender la ciudad. Asimismo, «en el caso de Nunca más el mar, son dos las estrategias privilegiadas para sobrevivir a pesar del dolor y el desencanto: el trabajo de la memoria y el humor»; además, Donoso Pareja dialoga textualmente con Vida del ahorcado, de Palacio, y Las cruces sobre el agua, de Gallegos Lara, de tal forma que en "x", el personaje, "coinciden las esferas de lo político y los afectos». ${ }^{23}$

$\mathrm{Al}$ trabajar con El rincón de los justos, Ortega pone los acentos en la recuperación que hace Velasco Mackenzie de lo popular urbano, así como de las formas particulares de la lectura y la escritura que tienen lugar en el barrio de Matavilela; una lectura asociada con un puesto de alquiler de revistas que tienen las mismas normas que la Biblioteca Municipal, y una escritura que es perpetrada en las sucias paredes de un baño público. «En este mundo, toda modalidad de práctica asociadas con la letrada es propositivamente lúdica, fragmentada, pública y cargada de erotismo». ${ }^{24}$

La lectura de La cofradía... le permite a Ortega no solo introducirse en los vericuetos de la religiosidad popular, que es el tema recreado por Alicia Yánez, sino en la observación de que un elemento común en sus novelas, y en otras escritas por mujeres, «tiene que ver con la construcción de un universo narrativo que pone el acento en la 'cuestión privada' como espacio clave en el ejercicio de la crítica al poder: el desnudamiento de sus secretos, la revelación de sus costuras», ${ }^{25}$ aunque sería una aseveración discutir pues el acento en la así llamada 'cuestión privada' es una característica general de la literatura, sea escrita por mujeres u hombres, ya que, justamente, la literatura está llamada a develar aquellos intersticios que constituyen "las pequeñas realidades" de las que hablaba Palacio en Débora, en contra de las "realidades grandes, voluminosas".

\footnotetext{
22 Ibíd., 330-1.

23 Ibíd., 352

24 Ibíd., 356.

25 Ibíd., 361.
} 
Ortega llega a la última década del siglo pasado identificándola como la década de la derrota, tras el final de la utopía socialista, pero que, al mismo tiempo, con la insurgencia del movimiento indígena se puso en cuestión al Estado mestizo, en contraposición con una sociedad pluricultural y un Estado plurinacional. Esta década, signada por variadas preocupaciones temáticas, es abordada por Ortega con el análisis de varias novelas, disímiles entre sí.

Natasha Salguero, con Azulinaciones, entrega una novela de afirmación femenina pero también de una escritura ágil que recupera la lengua coloquial, la coba, en un juego de planos superpuestos y diversidad de voces narrativas. El devastado jardín del paraíso, de Alejandro Moreano, construye una novela en la que el tratamiento moroso de las vidas íntimas de los sujetos van entretejiendo el camino que los lleva al encuentro del sujeto con la historia: «En esta perspectiva, el hito más importante que la novela detenidamente relata es la ocupación de la 'zona guerrillera' y la etapa final del devenir guerrillero: la 'muda de piel' al momento de vestir el uniforme verde oliva, tomar la metralleta y ocupar la zona. Momento que coincide, trágicamente, con su derrota ante un persistente cerco militar». ${ }^{26}$

Ortega pasa revista también a El otro lado de las cosas, de Francisco Proańo, novela que se organiza alrededor de la sospecha: «la realidad física y tangible esconde un orden oculto que se deja intuir a través de signos que marcan el engranaje cotidiano de las cosas». ${ }^{27}$ Resígnate a perder, de Javier Ponce, presenta a un personaje vaciado de ideales, carente de anclaje histórico, en la que sobresale "la dimensión del 'ritual' en la tematización del deseo homosexual». ${ }^{28}$ El viajero de Praga, de Javier Vásconez, novela imbuida en el exilio interior de su protagonista, parecería llevar a la pregunta que Ortega propone al final de su análisis: «¿cultivo del hastío y regreso a imágenes de un pasado perdido como expresión de un difícil enfrentamiento a un mundo en radical proceso de transformación?». ${ }^{29}$ Dos novelas de Carlos Carrión, El deseo que lleva tu nombre y Una niña adorada, llevan a Ortega a desarrollar la tesis de la crisis de masculinidad, soledad y descreimiento, partir del viejo profesor de gramática, Juventino Vargas, de alguna manera hermanado con el Santos Feijó, de la novela de Ponce, y el doctor Kronz, de Vásconez. Todo esto le permite sintetizar:

Varios estudios críticos han reconocido en la narrativa de los noventa el retorno al individuo en sus argumentos, reducido casi a su sola y fragmentada subjetividad en una suerte de 'exilio interior', frente a un progresivo desencanto y el consecuente despojamiento de viejas certidumbres. Se trata del 'exilio interior' en el que encuentran refugio los nuevos antihéroes de nuestra literatura que, por otro lado, cuentan con un importante antecedente en algunos personajes onettianos $[\ldots]$

26 Ibíd., 388.

27 Ibíd., 393.

28 Ibíd., 403.

29 Ibíd., 407. 
El libro de Ortega cierra su análisis de textos con la lectura de tres novelas que, según la autora, "interpelan al presente": Hoy empiezo a acordarme, de Miguel Donoso Pareja, Ciudad sin ángel, de Jorge Enrique Adoum, y Acoso textual, de Raúl Vallejo. La novela de Donoso es un viaje en torno a la memoria erótica, desde una visión masculina: «el tema del Don Juan atraviesa la novela; no solamente en la representación de su protagonista, sino en una explícita intertextualidad que incorpora citas, fragmentos y personas de las diferentes versiones de Don Juan»; ${ }^{30}$ pero también es una novela que incorpora la realidad histórica a la construcción del protagonista, quien en las postrimerías, comparte el final de muerte que les toca a los miembros de grupo Alfaro Vive: «Por más que J se define en su decisión de habitar una 'soledad sin orillas', de navegar sin la idea de un puerto fijo; aún en la intimidad de su espacio privado -único soporte de una recurrente memoria erótica, cuyo lema parecer ser 'vivir es recordar'- el protagonista se va alcanzado por las balas, injustas, de la historia». ${ }^{31}$

En Bruno, el personaje protagónico de la novela de Adoum, Ortega ve las condiciones del pos exilio, y cuyo regreso al país lo lleva a interpelar las contradicciones de la democracia que le toca vivir en un tiempo inaugural, «en suma, de un presente vital que le impide toda posibilidad de arraigo y lo condena a una suerte de no-lugar, o, en el mejor de los casos, al exilio en el arte que no es sino una forma de enclaustramientom. ${ }^{32}$ Ortega concluye la mirada sobre la novela del siglo veinte con Acoso textual (1999), "cuya voz narrativa habla bajo el enmascaramiento de diferentes identidades, en los diálogos que mantiene con anónimos 'internautas' en el espacio cibernético. En plena torsión del siglo, la novela da cuenta del impacto de las nuevas tecnologías en la construcción del sujeto, en ese juego de 'ser nadie y muchos a la vez'; acaso en el lugar de mayor extraterritorialidad posible: el mundo virtual del ciberespacio». ${ }^{33}$

El segmento final del libro “¿Desde dónde nos leemos?”, estructurado a manera de conclusiones, es una lúcida revisión de lo que significa leer nuestra literatura como el proceso que se construye en una tradición. Ortega seńala que esta construcción se ha dado con debates intensos, como el de Gallegos Lara y Palacio en referencia a las tareas políticas del escritor y la noción de literatura, concluyendo que "con las perspectiva del tiempo, cabe reconocer que ambos escritores estaban más cerca de lo que ellos podrían percibir. La mirada de ambos corresponde a la del 'expositor', para quien la realidad es 'repelente'».34 Ortega señala, con razón, que la pregunta a la que se volvió, de manera obsesiva, fue aquella referida al lugar y al papel del intelectual en la historia.

30 Ibíd., 417.

31 Ibíd., 418-9.

32 Ibíd., 421.

33 Ibíd., 423.

34 Ibíd., 436. 
Ortega lleva adelante una amplia argumentación en la que pone a dialogar dos textos que exponen visiones contrapuestas frente al lugar de enunciación y la noción misma de novela; el uno, "Entre la permanencia y el éxodo», de Alejandro Moreano, y el otro, "El síndrome de Falcón», de Leonardo Valencia. Este último sostiene que la carga de la realidad política y la búsqueda de identidad, representada por Falcón, el militante que llevaba sobre sus hombros a Gallegos Lara, ha sido una suerte de impedimento para la libertad del artista y una rémora para la creación pues se ha privilegiado el contenido por encima de la coherencia e interacción de las partes de una novela. Además, la idea de que el Ecuador es una frontera imaginaria y que lo que existe es un espectro más amplio llamado 'idioma español', se esgrime con un afán de cosmopolitismo. "Tal concepción de la lengua, como el lugar en donde se anulan las identidades y la geografía, es asimilada por Moreano a una condición de 'colonialidad' que provoca el divorcio del lenguaje literario y las hablas vivas (que son las verdaderas fuentes de renovación literaria)». ${ }^{35}$

Alicia Ortega ubica el planteamiento de Valencia en una tendencia crítica de los noventa que se pretende "extraterritorial", incrustada en las "ilusiones de la globalización”, y que, en una suerte de curiosa prestidigitación, convierte al exilio y la migración, en una situación de prestigio y celebración. Esta tendencia se ancla en un discurso excluyente en el que lo local y la tradición son categorías vistas como negativas mientras que lo cosmopolita y la modernidad es lo deseado. Ortega desnuda el sentido maniqueo de este planteamiento:

Asimila toda referencialidad al país como una tarea de instrumentalización de la literatura, así como toda perspectiva subjetiva es leída como 'voluntad estilística' y 'acabamiento formal'. Más grave aún, la metonimia aludida en el 'Síndrome de Falcón' congela el desarrollo de la literatura ecuatoriana en la década de los treinta. ${ }^{36}$

Fuga hacia adentro. La novela ecuatoriana en el siglo XX, de Alicia Ortega, es una obra monumental que reflexiona y pasa revista a la producción novelística del Ecuador durante el siglo pasado. El ensayo de Ortega, por la seriedad de su investigación, por la fuerza de sus argumentos, y por su escritura diáfana y fluida, está llamado a convertirse, dentro de la tradición de la crítica ecuatoriana, en la continuidad y superación de la obra de Rojas, para entender la novela del siglo veinte en Ecuador.

\section{Referencias}

Handelsman, Michael. "Alicia Ortega Caicedo. Fuga hacia adentro. La novela ecuatoriana

35 Ibíd., 444.

36 Ibidem, p. 449. 
en el siglo XX”. Pie de página, \# 1 (Guayaquil), octubre 2018, 137-142.

Mariátegui, José Carlos. "Arte, revolución y decadencia”, inicialmente publicado en la revista

Amauta, \# 3 (Lima, noviembre 1926) No 3, 3-4. Tomado del sitio web donde están subidas las obras completas de José Carlos Mariátegui: https://www.marxists. org/espanol/mariateg/oc/el_artista_y_la_epoca/paginas/arte\%20revolucion\%20 y\%20decadencia.htm

Ortega, Alicia. Fuga hacia dentro. La novela ecuatoriana en el siglo XX. Buenos Aires, Corregidor / Universidad Andina Simón Bolívar, Sede Ecuador, 2018.

Rojas, Ángel Felicísimo. La novela ecuatoriana, en Obras completas. Ensayo, Tomo III. Loja, Universidad Técnica Particular de Loja, 2004, 53-283. 